\title{
Integrated biorefineries, circular bio-economy, and valorization of organic waste streams with respect to bio-products
}

\author{
A. E. Atabani ${ }^{1} \cdot$ Vinay Kumar Tyagi ${ }^{2} \cdot$ Gislaine Fongaro $^{3} \cdot$ Helen Treichel $^{4} \cdot$ Arivalagan Pugazhendhi $^{5}$. \\ Anh Tuan Hoang ${ }^{6}$
}

Published online: 27 October 2021

(c) The Author(s), under exclusive licence to Springer-Verlag GmbH Germany, part of Springer Nature 2021

As a result of the linear economy, growing population, and increasing resource consumption, humanity is seriously challenged by the generation of waste in large quantities from various sectors. Organic waste (OW), animal waste (AW), and municipal solid waste (MSW) represent the major groups of waste generated by these sectors. Options of applying such organic waste streams as feedstock for producing both energy and bio-based products are referred to as biorefineries. The respective integrated concepts have received significant attention in recent years as a sustainable alternative to petroleum refineries, exploiting bio-waste for producing high-value products. Thus, such waste biorefineries represent a promising opportunity for moving up the waste hierarchy through the coupling of the waste and production sectors integrated within a future circular bio-economy. This has been gaining attention as a key concept for developing closed-loop technical and biological cycles. The concept of the circular economy, a system in which the final disposal of waste and by-products is minimized by promoting their reuse and valorization, can be successfully applied to bio-based production

A. E. Atabani

aeatabani@gmail.com; a.atabani@erciyes.edu.tr

1 Alternative Fuels Research Laboratory (AFRL), Energy Division, Department of Mechanical Engineering, Faculty of Engineering, Erciyes University, 38039 Kayseri, Turkey

2 Department of Civil Engineering, Indian Institute of Technology Roorkee, Roorkee, Uttarakhand 247667, India

3 Laboratory of Applied Virology, Department of Microbiology, Immunology and Parasitology, Federal University of Santa Catarina (UFSC), Florianópolis, SC 88034-000, Brazil

4 Laboratory of Microbiology and Bioprocesses, Federal University of Fronteira Sul, Erechim, Brazil

5 School of Renewable Energy, Maejo University, Chiang Mai 50290, Thailand

6 Institute of Engineering, Ho Chi Minh City University of Technology (HUTECH), Ho Chi Minh City, Vietnam chains. Many countries have already begun efforts to stimulate the transition towards such a circular bio-economy, fostering the promotion of sustainable and resource-efficient policies for long-term socio-economic and environmental benefit. The core principle of the circular bio-economy should facilitate the safe recycling and reuse of material directed towards the establishment of integrated sustainable approaches elaborating holistic resource utilization.

This thematic issue received a huge number of research and review papers from scientific fraternity across the globe. The following criteria were considered in selecting which of these papers to include: novelty, advancement provided to the existing knowledge of the nominated research areas, and relevance to the scope of Biomass Conversion and Biorefinery. Among the articles received, 32 original and review articles were accepted for inclusion, covering the diverse streams of biomass waste, i.e., forestry residues, agricultural residue (straw, husk, leaves, shell, stem, peel, stalk, stubble, bagasse, pulp, etc.), animal waste (animal and poultry manure), industrial bio-waste from processing of food and non-food products, biosludge (municipal and industrial), municipal solid bio-waste, and algal biomass. The aforementioned biomass wastes have been utilized to provide a wide range of energy carrier and other value-added products (i.e., biodiesel, methane, biogas, protein, variety of acids, ethanol, and lipids) through the application of biological, physical, chemical, and/or mechanical pre/ treatment routes. We firmly believe that this thematic issue will contribute to our collective knowledge of bio-waste valorization in a future circular bio-economy. We also believe that the diverse selection of original and review articles will benefit the scholars, academicians, practice engineers, and scientists in the field, serving as an informative source of successful case studies. The waste to bio-based approach will help to provide a roadmap towards a circular, safe, and sustainable bio-economy.

Publisher's note Springer Nature remains neutral with regard to jurisdictional claims in published maps and institutional affiliations. 